\title{
OSCILLATORITY OF FRESNEL INTEGRALS AND CHIRP-LIKE FUNCTIONS
}

\author{
Maja Resman, Domagoj Vlah and Vesna Županović
}

Abstract. In this review article, we present results concerning fractal analysis of Fresnel and generalized Fresnel integrals. The study is related to computation of box dimension and Minkowski content of spirals defined parametrically by Fresnel integrals, as well as computation of box dimension of the graph of reflected component function which are chirp-like function. Also, we present some results about relationship between oscillatority of the graph of solution of differential equation, and oscillatority of a trajectory of the corresponding system in the phase space. We are concentrated on a class of differential equations with chirp-like solutions, and also spiral behavior in the phase space.

Mathematics subject classification (2010): 28A12, 28A75, 37C45, 34C15.

Keywords and phrases: box dimension, oscillations, Fresnel integral, Bessel function, clothoid, chirp, spiral, wavy spiral.

\section{REFERENCES}

[1] R.P. Agarwal, S.R. Grace, D. O'Regan, Oscillation theory for second order linear, half-linear, superlinear and sublinear dynamic equations, Kluwer Academic Publishers, London, 2002.

[2] E. Barlow, A.J. Mulholland, A. Nordon, A. Gachagan, Theoretical analysis of chirp excitation of contrast agents, Phys. Procedia, 3 (2009), 743-747.

[3] P. Borgnat, P. Flandrin, On the chirp decomposition of Weierstrass-Mandelbrot functions, and their time-frequency interpretation, Appl. Comput. Harmon. Anal. 15 (2003), 134-146.

[4] M. BORN, E. WOLF, Principles of optics: Electromagnetic theory of propagation, interference and diffraction of light, Fourth edition. Pergamon Press, Oxford, 1970.

[5] E.J. Cande's, P.R. Charlton, H. Helgason, Detecting highly oscillatory signals by chirplet path pursuit, Appl. Comput. Harmon. Anal. 24 (2008), 14-40.

[6] W.A. CopPel, Stability and asymptotic behavior of differential equations D.C. Heath and Co., Boston, 1965.

[7] E.V. Degtiarova-Kostova, V.P. Kostov, Suboptimal paths in a planar motion with bounded derivative of the curvature, C. R. Acad. Sci. Paris, 321 (1995), 1441-1447.

[8] N. Elezović, V. Županović, D. Žubrinić, Box dimension of trajectories of some discrete dynamical systems, Chaos Solitons Fractals 34, 2 (2007), 244-252.

[9] A. Erdélyi, W. Magnus, F. Oberhettinger, F.G. Tricomi, Higher Transcendental Functions, Vol I, II, McGraw Hill (1953)

[10] Euler Integrals and Euler's Spiral - Sometimes called Fresnel Integrals and the Clothoide or Cornu's Spiral (unsigned), Amer. Math. Monthly 25 (1918), 276-282.

[11] K. FalConer, Fractal Geometry, Chichester: Wiley (1990).

[12] J. P. Françoise, Oscillations en biologie, Analyse qualitative et modeles, Mathématiques \& Applications, 46. Springer-Verlag, Berlin, 2005.

[13] P. Hartman, Ordinary differential equations, second ed., Birkhäuser, Boston, Basel, Stuttgart, 1982. 
[14] L. Horvat Dmitrović, Box dimension and bifurcations of one-dimensional discrete dynamical systems, Discrete Contin. Dyn. Syst. 32, 4 (2012), 1287-1307.

[15] S. JAFFARD, Y. MEYER, Wavelet methods for pointwise regularity and local oscillations of functions, Mem. Amer. Math. Soc. 123 (1996), 1-110.

[16] M. KePesi, L. Weruaga, Adaptive chirp-based time-frequency analysis of speech signals, Speech Commun. 48 (2006), 474-492.

[17] I.T. KiguradZE, T.A. ChantURIA, Asymptotic properties of solutions of nonautonomous ordinary differential equations, Kluwer Academic Publishers Group, Dordrecht, 1993.

[18] L. Korkut, M. Resman, Fractal oscillations of chirp-like functions, Georgian Math. J., 19, 4 (2012), 705-720.

[19] L. Korkut, D. Vlah, V. Županović, Fractal properties of Bessel functions, submitted, arXiv:1304.1762.

[20] L. Korkut, D. Vlah, D. Žubrinić, V. Županović, Generalized Fresnel integrals and fractal properties of related spirals, Appl. Mathematics and Computation, 206 (2008), 236-244.

[21] L. Kor Kut, D. Vlah, V. ŽUPAnOvić, Geometrical and fractal properties of a class of systems with spiral trajectories in $\mathbb{R}^{3}$, submitted, arXiv:1211.0918.

[22] L. Korkut, D. Vlah, D. ŽUbrinić, V. ŽUpanović, Wavy spirals and their fractal connection with chirps, submitted, arXiv:1210.6611.

[23] L. Korkut, D. ŽUbrinić, V. ŽUPAnović, Box dimension and Minkowski content of the clothoid, Fractals, 17 (2009), 485-492.

[24] C.Q. HE, M.L. LAPIDUs, Generalized Minkowski content, spectrum of fractal drums, fractal strings and the Riemann zeta-function, Mem. Amer. Math. Soc. 127, 608 (1997).

[25] S.G. KrantZ, H.R. Parks, The Geometry of Domains in Space, Birkhäuser Advanced Texts, Birkhäuser Boston, Inc., Boston, MA (1999).

[26] T. KusAno, Y. NAITO, Oscillation and nonoscillation criteria for second order quasilinear differential equations, Acta Math. Hungar. 76 (1997), 81-99.

[27] T. Kusano, Y. Naito, A. Ogata, Strong oscillation and nonoscillation of quasilinear differential equations of second order, Differential Equations Dynam. Systems, 2 (1994), 1-10.

[28] M.K. KWOng, M. PašIĆ, J.S.W. Wong, Rectifiable oscillations in second-order linear differential equations, J. Differ. Equ. 245, 8 (2008), 2333-2351.

[29] M.L. LAPIDUS, Vibrations of fractal drums, the Riemann hypothesis, waves in fractal media, and the Weyl-Berry conjecture, Ordinary and Partial Differential Equations, vol. IV, Pitman Research Notes in Math. Series, 289, Longman Scientific and Technical, London (1993), 126-209.

[30] M.L. Lapidus, M. VAn Frankenhuysen, Fractal Geometry and Number Theory, Complex Dimensions of Fractal Strings and Zeros of Zeta Functions, Birkhäuser (2000).

[31] N. N. Lebedev, Special Functions and Their Applications, Dover, 1972.

[32] P. Mardešść, M. Resman, V. ŽUpanović, Multiplicity of fixed points and $\varepsilon$-neighborhoods of orbits, J. Differ. Equ. 253 (2012), 2493-2514.

[33] P. Mattila, Geometry of Sets and Measures in Euclidean Spaces, Fractals and Rectifiability, Cambridge University Press (1995).

[34] D.S. Meek, D.J. Walton, A controlled clothoid spline, Computers \& Graphics, 29 (2005), 353-363.

[35] D.S. MeeK, D.J. Walton, Clothoid spline transition spirals, Math. Comp. 59 (1992), 117-133.

[36] D.S. MEeK, D.J. WALTON, The use of Cornu spirals in drawing planar curves of controlled curvature, J. Comput. Appl. Math. 25 (1989), 69-78.

[37] Y. Meyer, H. Xu, Wavelet analysis and chirps, Appl. Comput. Harmon. Anal. 4 (1997), 366-379.

[38] D. O'REgAn, Existence theory for nonlinear ordinary differential equations, Kluwer, 1997.

[39] T. PaAvle, M. Min, T. PARVE, Using of chirp excitation for bioimpedance estimation: theoretical aspects and modeling, Proc. of the Baltic Electronics Conf. BEC2008 (2008), Tallinn, Estonia, 325328.

[40] M. PAŠIĆ, Fractal oscillations for a class of second-order linear differential equations of Euler type, J. Math. Anal. Appl., 341 (2008), 211-223.

[41] M. PAŠIĆ, Rectifiable and unrectifiable oscillations for a class of second-order linear differential equation of Euler type, J. Math. Anal. Appl. (2007), 724-738.

[42] M. PAŠIĆ, A. RAGUŽ, Rectifiable Oscillations and Singular Behaviour of Solutions of Second-Order Linear Differential Equations, Int. Journal of Math. Analysis, 10, 2 (2008), 477 - 490. 
[43] M. PAŠIĆ, S. TANAKA, Fractal oscillations of self-adjoint and damped linear differential equations of second-order, Appl. Math. Comp. 218 (2011), 2281-2293.

[44] M. PAŠIĆ, J.S.W. WONG, Rectifiable oscillations in second-order half-linear differential equation, Annali di matematica pura ed aplicata, 188, 3 (2009), 515-541.

[45] M. PAŠIĆ, D. ŽUBRINIĆ, V. ŽUPANOVIĆ, Oscillatory and phase dimensions of solutions of some second-order differential equations, Bull. Sci. Math. 3 (2009), 859-874.

[46] M.H. Pedersen, T.X. Misaridis, J.A. Jensen, Clinical evaluation of chirp-coded excitation in medical ultrasound, Ultrasound Med. Biol. 29 (2003), 895-905.

[47] G. Ren, Q. Chen, P. Cerejeiras, U. Kähler, Chirp transforms and chirp series, J. Math. Anal. Appl. 373 (2011), 356-369.

[48] M. RESMAn, Epsilon-neighborhoods of orbits and formal classification of parabolic diffeomorphisms, Discrete Contin. Dyn. Syst. 33, 8 (2013), 3767-3790.

[49] C. Tricot, Curves and Fractal Dimension, Springer-Verlag (1995).

[50] L. Weruaga, M. KéPesi, The fan-chirp transform for nonstationary harmonic signals, Signal Process. 87 (2007), 1504-1522.

[51] J.S.W. Wong, On rectifiable oscillation of Euler type second-order linear differential equations, E. J. of Diff. Eqn. 20 (2007) 1-12.

[52] D. ŽUBRINIĆ, Analysis of Minkowski contents of fractal sets and applications, Real Anal. Exchange, 31, $2(2005 / 06), 315-354$.

[53] D. ŽUbrinić, V. ŽUPANOVIĆ, Fractal analysis of spiral trajectories of some vector fields in $\mathbb{R}^{3}$, C. R. Acad. Sci. Paris, Série I, 342, 12 (2006), 959-963.

[54] D. Žubrinić, V. ŽuPANOviĆ, Fractal analysis of spiral trajectories of some planar vector fields, Bulletin des Sciences Mathématiques, 129, 6 (2005), 457-485.

[55] D. ŽUbrinić, V. ŽUPANOVIĆ, Poincaré map in fractal analysis of spiral trajectories of planar vector fields, Bull. Belg. Math. Soc. Simon Stevin, 15 (2008) 947-960.

[56] V. Županović, D. Žubrinić, Fractal dimensions in dynamics, Encyclopedia of Mathematical Physics, eds. J.-P. Françoise, G.L. Naber and Tsou S.T. Oxford: Elsevier, 2 (2006), 394-402. 